\title{
Improvements in primary care skills and knowledge with a vocational training program - a pre-post survey
}

This article was published in the following Dove Press journal:

Advances in Medical Education and Practice

27 July 2017

Number of times this article has been viewed

\section{Sima Djalali \\ Ryan Tandjung \\ Thomas Rosemann \\ Stefan Markun}

Institute of Primary Care, University of Zurich, University Hospital Zurich, Zurich, Switzerland
Correspondence: Sima Djalali Institute of Primary Care, University of Zurich, University Hospital of Zurich, Pestalozzistrasse 24, CH-809I Zurich, Switzerland Email sima.djalali@usz.ch
Background: Facing the upcoming shortage of primary care physicians (PCPs), medical and governmental organizations have recently made major investments to foster vocational training programs in Switzerland, designed to provide context-specific training for trainees in primary care practices. Less is known about the impact of these programs on the skills and specific knowledge of trainees. We aimed to evaluate the Cantonal program for vocational primary care training in the Canton of Zurich, Switzerland's largest Canton.

Methods: We undertook a pretest-posttest study and surveyed physicians before and after participating in the Cantonal program for vocational primary care training in the Swiss Canton of Zurich. All trainees who participated in the program from 2013 until the end of 2015 were eligible. Primary outcome was the proportion of trainees being confident about their professional, organizational, examination and management skills before and after completing vocational training. Secondary outcomes were the proportion of trainees stating knowledge gain in entrepreneurship and the proportion of trainees being motivated to pursue a career as PCP.

Results: Data of 47 trainees participating in the vocational training between 2013 and 2015 were eligible. In total, 35 (74.5\%) participated in the T1 survey and $34(72.3 \%)$ in the T2 survey. At $\mathrm{T} 2$, significantly more trainees (T1: $11 \%-89 \%, \mathrm{~T} 2: 79 \%-100 \%)$ stated to be at least "slightly confident" about their skills ( $p<0.05$ for each individual skill). Knowledge gain in entrepreneurship was highly expected and experienced by the trainees $(55 \%-77 \%$ of respondents $)$ in case of medicine-specific contents, but hardly expected in case of general business contents $(\leq 47 \%$ of respondents). Concerning trainees' motivation to pursue a career as PCP, we observed only a minimal, statistically insignificant change, suggesting that the vocational training did not alter trainees' preconceived career plans as PCP.

Conclusion: Given the measured increase in confidence, evaluation of training programs should focus on operationalizing key skills of PCPs. Given the lack of change in trainees' motivation; however, statements about the effect of program implementation on national shortage of PCPs cannot be made.

Keywords: primary care, career choice, physicians, family/trends, internship and residency/ trends, Switzerland, surveys, questionnaires

\section{Background}

Swiss health care is challenged by a shortage of primary care physicians (PCPs). PCPs retiring within the next few years outnumber the number of medical students and young physicians who perceive primary care as an attractive career choice. ${ }^{1,2}$ Supporting young physicians in becoming PCPs is of interest and several studies have shown that time spent in primary care increases the likelihood of young physicians to become PCPs. ${ }^{3-5}$ 
Particularly time of residency is in the focus, since residency was shown much more determining concerning future career choice than medical school. ${ }^{6}$ Unfortunately, studies have also shown that many residents initially interested in a career in primary care are discouraged during their vocational training and seek different career paths afterwards. ${ }^{7,8}$

In Switzerland, vocational training in primary care during residency has been introduced in the late 90s. Facing the upcoming shortage of PCPs, medical as well as governmental organizations have recently made major investments to foster vocational training programs, designed to provide context-specific training for trainees in primary care practices. ${ }^{9}$ Despite the long tradition of these programs, data on outcomes of such programs is scarce. We aimed to evaluate the Cantonal program for vocational primary care training in the Canton of Zurich, Switzerland's largest Canton. We were particularly interested to investigate participating trainees' gain in skills and knowledge during vocational training, and the influence on trainees' future career plans.

\section{Methods}

We undertook a pretest-posttest study and surveyed physicians before and after participating in the Cantonal program for vocational primary care training in the Swiss Canton of Zurich as trainees.

\section{Outcomes}

Primary outcome of the study was the proportion of trainees being confident about their professional, organizational, examination and management skills before and after completing vocational training.

Secondary outcomes were the proportion of trainees stating knowledge gain in entrepreneurship during the training, and the proportion of trainees being motivated to pursue a career as PCP before and after completing the training.

\section{Setting and participants}

The Cantonal program for vocational primary care training in the Swiss Canton of Zurich is managed by the Institute of Primary Care, University and University Hospital of Zurich. Trainees who participate in the program are employed by the Institute of Primary Care and pass their training in affiliated primary care practices, supervised by teaching physicians. Trainees regularly receive advanced group training courses on clinical topics. Besides, content and teaching format are not regulated. Teaching physicians are free to design the training individually. The following requirements are imposed on teaching physicians:
- Professional license valid in Switzerland.

- Swiss medical board certification in General Internal Medicine or Pediatrics.

- Teaching license of the Institute for Postgraduate and Continuous Education of the Swiss Medical Association.

- Diploma for Continuing Medical Education (CME) of the Medical Society for General Internal Medicine or Pediatrics.

- Complete training course in teaching medical students and residents.

Training duration is 6 months for a full-time employment, or longer if participants chose a part-time employment. Trainees are required to have spent at least 2 years in inpatient internal medicine residency. Applicants need to submit a written application and are selected into the program after passing an unstructured interview led by staff of the Institute of Primary Care, University and University Hospital of Zurich. Acceptance rate is $95 \%$. So far, the primary reason for the rejection of applicants was their lack of previous clinical experience. The program and collection of data started in the year 2013. All trainees who participated in the program until the end of 2015 were eligible.

\section{Data collection and questionnaire}

All trainees participating in the program were invited to the survey at the beginning of the training (T1) and at the end of the training (T2).

The survey was performed using a self-administered online questionnaire comprising a total of 11 items at $\mathrm{T} 1$ and 23 items at T2. At T1 and T2, 8 items asked for self-evaluated skills and career choices. In addition, at T2 only, 1 additional item queried knowledge gain in entrepreneurship.

Regarding self-evaluation of skills, trainees were asked to rate their confidence in four dimensions of skills on a 6-point Likert scale: 1) professional skills (recognition and differential diagnosis of diseases, generate and test working hypotheses, interpret results and initiate therapies), 2) organizational skills (prioritize health problems and organize treatment accordingly, provide out-of-practice care, efficiently communicate with other health professionals), 3) examination skills (efficiently use examinations and understand limits of diagnostic measures in primary care) and 4) management skills (draw up tailored treatment plans and take responsibility of long-term care for patients). The scale ranged from "completely unconfident" (1 point) to "completely confident" (6 points). In addition, an opt-out answer ("I do not know") was provided. 
We categorized the inquired skills into two categories, first "basic skills" and second "specific primary care skills". For the latter we included skills characteristic for PCPs in their role as care coordinators and providers of continuous patient-centred chronic care. Namely these were the skills to "make optimal use of time between two encounters of a patient for case management" (organizational skill), "prepare home visits and cope with reduced diagnostic tools when seeing patients at their home" (organizational skill), "understand limits of diagnostic measures in practice and refer the patient if necessary" (examination skill), "draw up a diagnostic and treatment plan tailored to patients' needs" (management skill), "manage the most prevalent chronic diseases" (management skill) and "provide long-term care for patients with multiple chronic diseases, particularly regarding medication adjustment" (management skill).

Knowledge gain in entrepreneurship was evaluated in seven dimensions of private practice business (payroll accounting, team leadership, facility management, health insurance business, billing and accountancy). Respondents were asked to state whether they had or had not expected a gain of knowledge on these topics and whether an expected knowledge gain had taken place at $\mathrm{T} 2$.

Concerning career choices, trainees were asked to declare their motivation to become a PCP (level of motivation on a scale from " 1 , very low" to " 6 , very high") and their preferred work setting (single vs group practice, self-employed vs employed, rural vs suburban or urban setting) and workload (percentage of full-time equivalent).

\section{Statistics}

Distributions of survey answers are presented as frequencies and percentages. If not indicated otherwise, all percentages refer to the total number of survey respondents who answered a particular item. Continuous variables are presented as mean and $\mathrm{SD}$ or median and interquartile range (IQR), minimum and maximum ( $\mathrm{min} / \mathrm{max})$. Paired Wilcoxon test was used to test comparisons between answer distributions of continuous variables, while Fisher's exact test and McNemar's test were used for ordinal and dichotomous variables, respectively. A $p$ value $<0.05$ was considered as statistically significant. All statistical analyses were done in $\mathrm{R}$ (version 3.2.4, The R Foundation for Statistical Computing, Vienna, Austria).

\section{Ethics approval and consent to participate}

According to current Swiss law on human research, surveys among physicians do not require an approval by the regional ethics committee. ${ }^{24}$ Completion of the survey was deemed to be consent to participate.

\section{Results Population}

Data of 47 trainees participating in the vocational training between 2013 and 2015 were eligible. Of these trainees, $40(85.1 \%)$ were female. Median age was 33 years (IQR 31-34). Trainees entered the program median 6 years (IQR $4.2-7)$ after graduation. Median length of preceding clinical experience was 4.8 years (IQR 3.5-5). Forty-four (93.6\%) had clinical experience as resident in internal medicine, $28(59.6 \%)$ in surgery, $13(27.7 \%)$ in otorhinolaryngology, $10(21.3 \%)$ in rheumatology, $9(19.1 \%)$ in dermatology, 6 $(12.8 \%)$ in psychiatry and $57.4 \%$ in other medical specialities. In total, 35 (74.5\%) participated in the T1 survey and $34(72.3 \%)$ in the T2 survey. Completeness of questionnaires was $100 \%$ at $\mathrm{T} 1$ and $94.3 \%$ at $\mathrm{T} 2$. Respondents did not significantly differ from nonrespondents in terms of age, sex and clinical experience. The trainees were each supervised by one of 32 teaching physicians ( 4 women, 28 men) with a mean of 1.0 years (SD 0.4) teaching experience since registration in the Cantonal program for vocational primary care training.

\section{Skills}

Confidence in five professional skills was inquired. At T1 across all professional skills, the average proportion of trainees who were at least "slightly confident" (score $\geq 4$ ) was $83.4 \%$ (SD $4.2 \%$ ). At T2, this measure increased to $98.8 \%$ (SD 1.5\%). Not only the overall confidence, but also the confidence in each individual professional skill increased significantly $(p<0.05$ for each individual skill). Figure 1 lists the skills and shows the according distribution of Likert scale ratings.

The most substantial increase was observed in the skill of selecting adequate diagnostic tools: the proportion of respondents who expressed confidence with a score $\geq 4$ increased from $77.1 \%(27 / 35)$ to $100 \%$ (33/33). The smallest increase was observed regarding the skill of initiating an indicated therapy for the most important diseases in primary care with $88.6 \%$ (31/35) assigning a score $\geq 4$ at $\mathrm{T} 1$ vs $97.0 \%$ $(32 / 33)$ at $\mathrm{T} 2$.

Similarly, nine organizational skills were inquired. Across all organizational skills, the average proportion of trainees who assigned a score $\geq 4$ was $67.0 \%$ (SD $21.7 \%$ ) at $\mathrm{T} 1$ and $90.2 \%$ (SD $13.5 \%$ ) at $\mathrm{T} 2$ also with significant increases in all individual organizational skills $(p<0.05)$. 


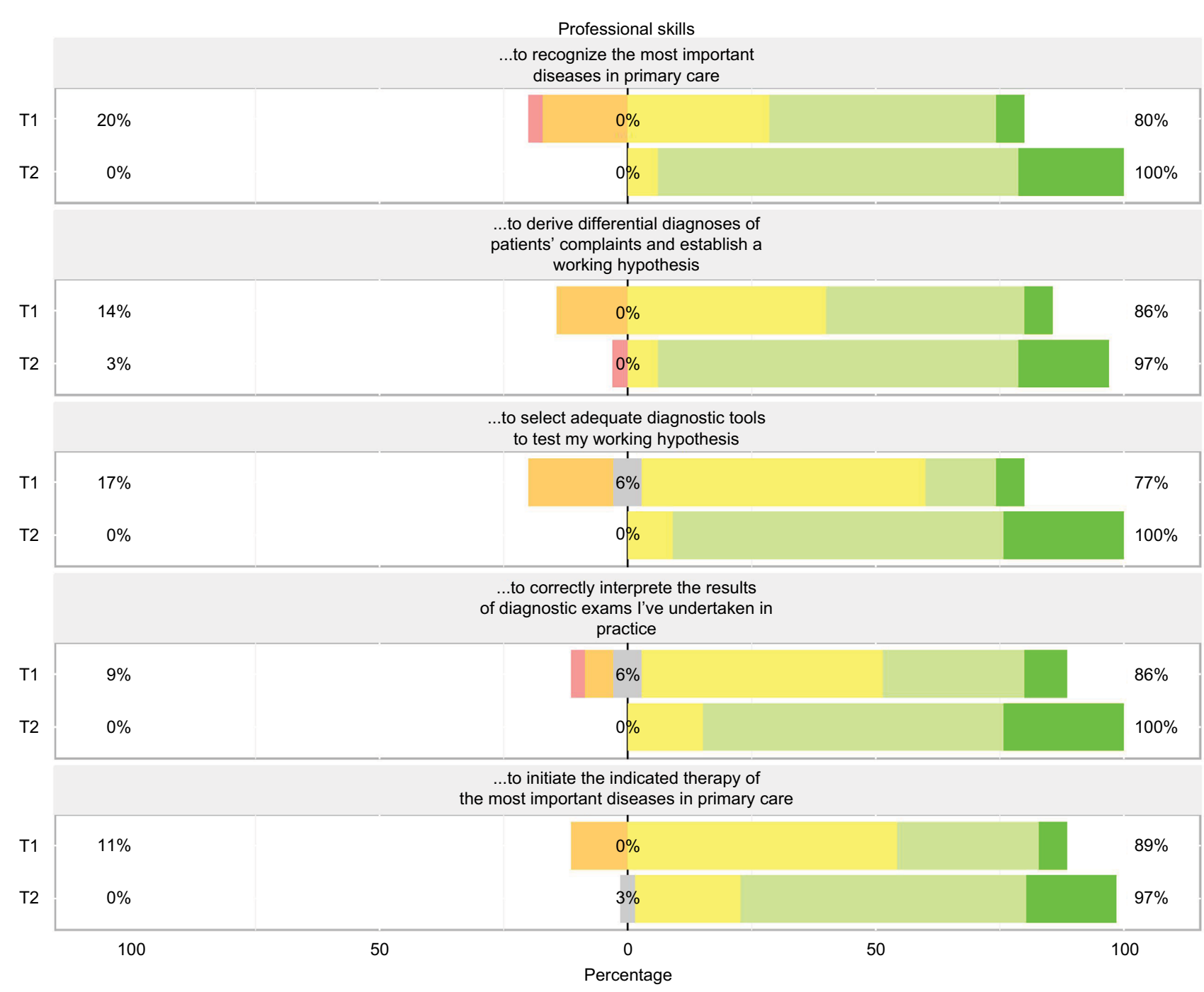

\begin{tabular}{|l|l|l|l|l} 
Mostly unconfident $\quad$ Slightly unconfident $\quad$ I do not know $\quad$ Slightly confident & Mostly confident
\end{tabular}

Figure I Likert scale ratings of professional skills.

Notes: T1 indicates the beginning of the training and T2 indicates the end of the training.

A list of the skills and the distribution of Likert scale ratings is provided in Figure 2. The most substantial increase of trainees assigning a score $\geq 4$ was observed regarding the two primary care specific skills in this domain: "make optimal use of time between two encounters of a patient for case management" $(65.7 \%, 23 / 35$ at T1 vs $100 \%, 34 / 34$ at T2), and "to prepare home visits and cope with reduced diagnostic tools when seeing patients at their home" (11.4\%, 4/35 at $\mathrm{T} 1$ vs $55.9 \%, 19 / 34$ at T2). The smallest increase was found regarding the skill of compiling all relevant information on a patient and phrasing a referral letter $(85.7 \%, 30 / 35$ at $\mathrm{T} 1 \mathrm{vs}$ $94.1 \%, 32 / 34$ at T2) and the skill of deriving relevant information on a patient from physician letters $(88.6 \%, 31 / 35$ at T1 vs $97.1 \%, 33 / 34$ at T2).
Concerning examination skills, four skills were inquired. Across examination skills, the average proportion of trainees who assigned a score $\geq 4$ rose from $73.9 \%$ (SD 14.4\%) at T1 to $99.3 \%$ (SD $1.3 \%$ ) at $\mathrm{T} 2$. The increases of confident trainees were statistically significant ( $p<0.05$ for all individual skills). Figure 3 lists the skills and shows the according distribution of Likert scale ratings.

The most substantial increase was observed concerning the primary care specific skill in this domain: "to understand the limits of diagnostic measures in practice and refer the patient if necessary" (50\%, 17/34 at T1 vs 100\%, 34/34 at T2). Smallest increase was observed concerning the skill of reducing physical examination to problem specific elements with $88.6 \%$ (31/35) assigning a score $\geq 4$ at $\mathrm{T} 1$ vs $100 \%(34 / 34)$ at $\mathrm{T} 2$. 


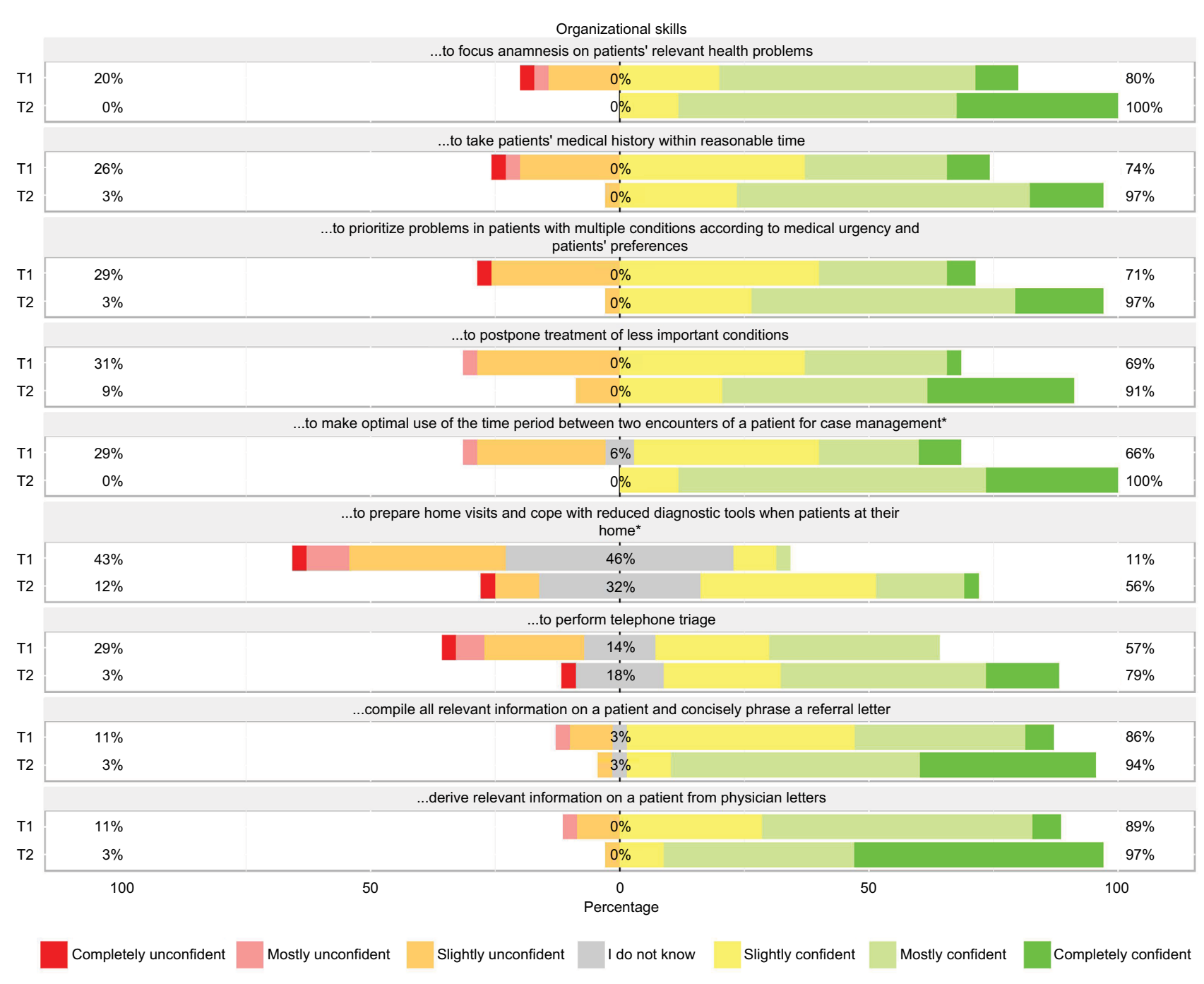

Figure 2 Likert scale ratings of organizational skills.

Notes: *Skills marked with an asterisk are classified as primary care specific skills. TI indicates the beginning of the training and T2 indicates the end of the training.

Concerning management skills, three skills were inquired, all of them classified as primary care specific skills (Figure 4). The average proportion of trainees who assigned a score $\geq 4$ was $53.3 \%$ (SD $12.0 \%$ ) of 35 respondents at $\mathrm{T} 1$ and $91.2 \%$ (SD $6.3 \%$ ) of 34 respondents at $\mathrm{T} 2$ (difference $p<0.05$ for all skills).

The most substantial increase was seen concerning the skill of providing long-term care for patients. The proportion of confident trainees was $37.1 \%(13 / 35)$ at $\mathrm{T} 1$ and $82.4 \%(28 / 34)$ at 2 . The smallest increase was observed regarding the skill of drawing up a diagnostic and treatment plan with $65.7 \%$ (23/35) assigning a score $\geq 4$ at $\mathrm{T} 1$ vs $97.1 \%(33 / 34)$ at $\mathrm{T} 2$.

\section{Entrepreneurship}

Most trainees had expected to gain knowledge on entrepreneurship during vocational training and stated that their expectations were met, particularly regarding knowledge on how to run a practice pharmacy (expectations met $76.5 \%$,
26/34; no expectations: $11.8 \%, 4 / 34$ ), how to lead a practice team (expectations met 67.6\%, 23/34; no expectations: 20.6\%, $7 / 34$ ), how to issue bills (expectations met 64.7\%, 22/34; no expectations: $26.5 \%, 9 / 34$ ), how to run a practice laboratory (expectations met 58.8\%, 20/34; no expectations: 26.5\%, 9/34) and knowledge on health insurance business (expectations met 54.5\%, 18/33; no expectations: $24.2 \%, 8 / 34$ ). However, there were exceptions: regarding knowledge on accountancy and payroll accountancy, most trainees did not expect to gain any knowledge in the first place (no expectations: $47.1 \%, 16 / 34$ both items). Consequently, the number of trainees who stated to have gained knowledge was low (expectations met: $26.5 \%, 9 / 34$ and $20.6 \%, 7 / 34$, respectively).

\section{Career choices}

At T1, 26/35 (74.3\%) of respondents declared to be highly (score $\geq 5$ ) motivated to pursue a career as PCP compared to 


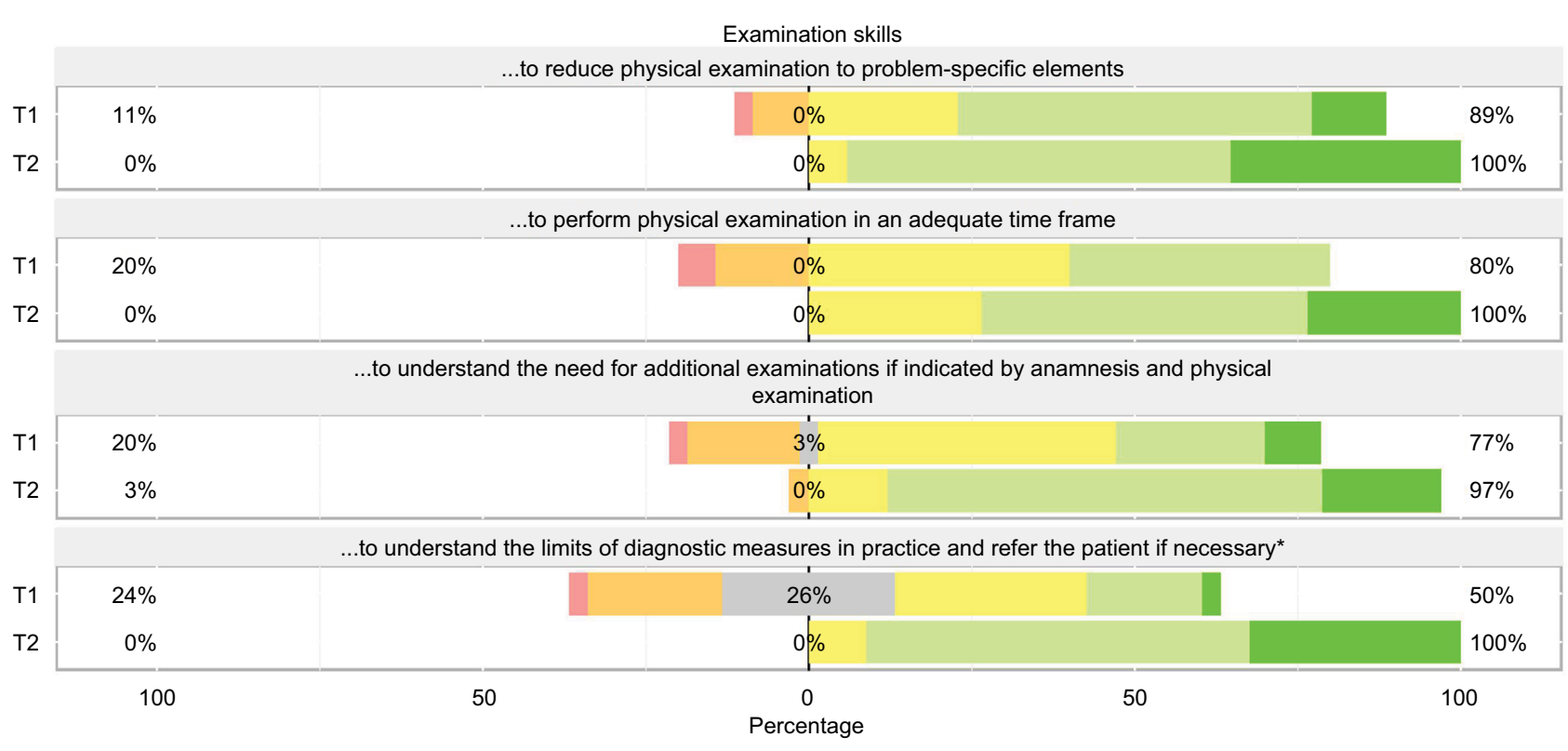

\begin{tabular}{|l|l|l|l|l|l} 
Mostly unconfident $\quad$ Slightly unconfident $\quad$ I do not know & Slightly confident & Mostly confident
\end{tabular}

Figure 3 Likert scale ratings of examination skills.

Notes: *Skills marked with an asterisk are classified as primary care specific skills. TI indicates the beginning of the training and T2 indicates the end of the training.

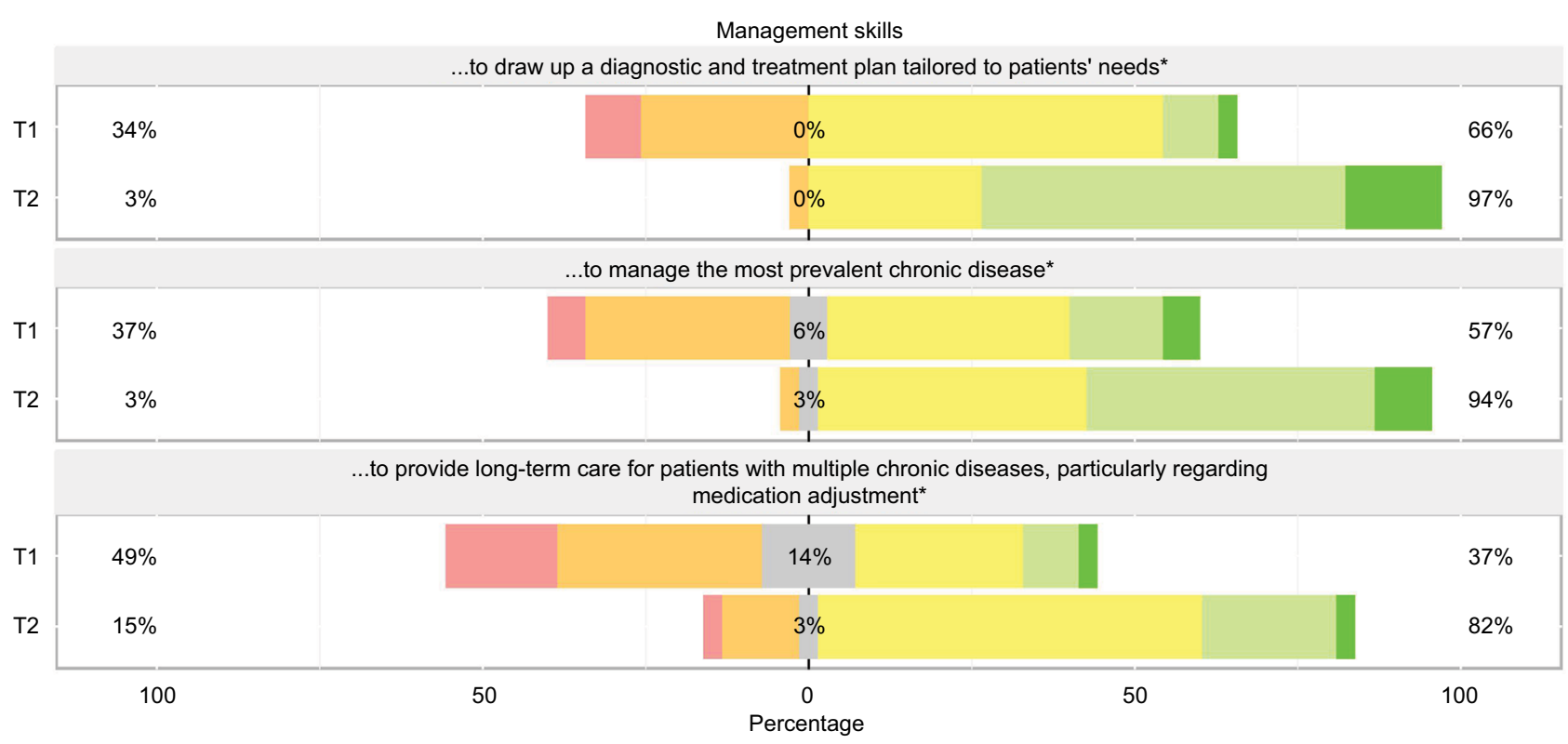

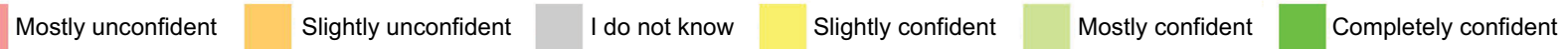

Figure 4 Likert scale ratings of management skills.

Notes: *Skills marked with an asterisk are classified as primary care specific skills. TI indicates the beginning of the training and T2 indicates the end of the training.

$30 / 34(88.2 \%)$ at T2 $(p=0.34)$. Respondents' median level of motivation increased from 5.5 (IQR 5-6) to 6 (IQR 5-6; $p=0.03$ ). The proportion of respondents who stated specific plans to settle down in a PCP practice increased from 6/35 $(17.1 \%)$ at $\mathrm{T} 1$ to $11 / 34(32.3 \%)$ at $\mathrm{T} 2(p=0.13)$.
Table 1 shows respondents' preferred work setting and workload as PCP. Changes in responses were insignificant. Both at $\mathrm{T} 1$ and $\mathrm{T} 2$, respondents preferred group practices over single handed practices, employment over self-employment and suburb locations over rural and urban locations. Mean 
Table I Career plans and preferred workload

\begin{tabular}{lll}
\hline Would you consider working & Yes TI & Yes T2 \\
\cline { 2 - 3 } as a PCP... & $\mathbf{n ~ ( \% )}$ & $\mathbf{n}(\%)$ \\
\hline In a single practice? & $2(6.5)$ & $\mathrm{I}(2.9)$ \\
In a double practice? & $21(67.7)$ & $22(64.7)$ \\
In a group practice? & $34(100)$ & $34(97.1)$ \\
As an employee? & $25(75.8)$ & $30(85.7)$ \\
Self-employed? & $16(53.3)$ & $18(52.9)$ \\
In an urban area? & $22(75.9)$ & $22(66.7)$ \\
In a suburban area? & $26(78.8)$ & $29(93.5)$ \\
In a rural area? & $19(59.4)$ & $18(54.5)$ \\
\hline Preferred workload as a & $\mathbf{T I}$ & $\mathbf{T 2}$ \\
PCP (\% of I FTE) & $\mathbf{n ~ ( \% )}$ & $\mathbf{n ~ ( \% )}$ \\
\hline $50 \%-59 \%$ & $3(8.6)$ & $4(11.8)$ \\
$60 \%-79 \%$ & $9(25.7)$ & $6(17.6)$ \\
$80 \%-100 \%$ & $23(65.7)$ & $24(70.6)$ \\
\hline
\end{tabular}

Notes: All comparisons between TI and T2 were statistically insignificant. TI indicates the beginning of the training and $\mathrm{T} 2$ indicates the end of the training.

Abbreviations: FTE, full-time equivalent; PCP, primary care physician.

preferred workload was $77 \%$ (SD $15 \%$ ) of one full-time equivalent.

\section{Discussion \\ Main results}

We here present the evaluation of the Cantonal vocational training program in the Canton of Zurich in the years 2013-2015 based on trainees' self-evaluation. The most substantial increase of the proportion of trainees being confident about their skills - was found regarding primary care specific skills. Regarding the other inquired skills, classified as basic skills of a clinician, trainees already stated a high confidence at the beginning of vocational training. The increase in the proportion of confident trainees at T2 was thus smaller, but still statistically significant.

Concerning the secondary outcome - the proportion of trainees stating a knowledge gain in entrepreneurship during vocational training - we observed most trainees being positive about their knowledge gain. Interestingly, however, trainees' expectations varied largely depending on the dimension of entrepreneurship. Particularly regarding knowledge on accountancy and payroll accounting - two not medicinespecific business issues - almost half of the participants declared not to have expected and experienced knowledge gain. By contrast, knowledge on rather medicine-specific business issues (e.g., how to run a practice pharmacy) was highly expected and experienced by the trainees.

At last, we examined trainees' motivation to pursue a career as PCP. We observed only a minimal, statistically insignificant change, suggesting that the vocational training did not alter trainees' preconceived career plans. Evidently, our study population already showed high levels of motivation to pursue a career in primary care when entering the program.

\section{Skills}

Although a number of vocational primary care trainings exist in Switzerland, ${ }^{9}$ data on skill development of trainees were lacking so far. For the first time, we investigated different dimensions of skills before and after vocational training by self-evaluation. In sum, 21 skills were inquired. Thereof, 6 were classified as primary care specific skills, that is, management skills and organizational and examination skills that are characteristic for PCPs in their role as care coordinators and providers of continuous patient-centred chronic care. Apparently, trainees' confidence in these skills showed large room for improvement at $\mathrm{T} 1$ at the beginning of their training and improved significantly. Participants' confidence in the other inquired skills increased significantly as well, but less, because of high baseline ratings at $\mathrm{T} 1$. This may be due to the fact that these skills (i.e., "take patients history within reasonable time") are not $\mathrm{PCP}$-specific and should characterize any physician with increasing clinical experience. The 3-4 years of clinical experience of the surveyed trainees explain the high baseline ratings with relatively small room for improvement. It is to note, that most Swiss institutions operating vocational training programs demand previous clinical experience of trainees. ${ }^{9}$ More efficient evaluation should, therefore, focus on items that assess key skills of PCPs rather than basic professional skills. Particularly team skills enabling organizational learning and adaption of patient-centred care models should be in focus. ${ }^{10}$ However, our results provide some evidence for a minimum of 3 years of experience to be a good foundation for basic professional skills allowing primary care teachers to focus on primary care specific skills during the vocational training. However, one could also question whether 3 years of experience in other settings are truly necessary and vote for the inclusion of less experienced trainees in order to shorten postgraduate training of PCPs and thereby stimulate a generation-turnover in primary care. Given the fact that a lack of previous clinical experience has been the main reason for the rejection of applicants in Zurich so far, lowering the experience requirement might be an option to reach more residents in the future.

\section{Entrepreneurship}

We further investigated respondents' knowledge gain in entrepreneurship. In the context of the Swiss health care system, this is important, because PCPs are traditionally entrepreneurs running their own practice. Our evaluation showed, however, 
that not all trainees presumed to acquire respective knowledge during vocational training in the first place. The less medicine-specific the dimension, the lower was the proportion of trainees who stated to expect a knowledge gain. This may be explained by the fact that most respondents preferred employment over self-employment as future PCPs. Renunciation of self-employment is a trend among young PCPs that has been shown in different other studies before. ${ }^{6,11-13}$ It can be speculated that the respondents took entrepreneurship as negligible due to their anticipated status as employee without business responsibility. Vocational training designers should nevertheless be capable of teaching primary care-specific business contents. First, because the majority of trainees still expect to learn business contents. Second, because such education addresses main barriers to a career in primary care: fear of too much administrative work and uncertainty about the income situation in primary care. ${ }^{14,15}$

\section{Effects on career}

Previous studies suggested that residency was much more determining for a career choice than medical school, ${ }^{6,16}$ and continuous contact to the primary care setting was shown to be an important factor for choosing a career in primary care. ${ }^{3,7,17}$ Vocational training in primary care is, therefore, often seen as crucial for workforce development. Our study is, however, not the one to prove this suspicion. Given the fact that participation in the Cantonal vocational training program of Zurich is voluntary, it is reasonable that it will primarily attract young physicians already interested in primary care. The results of our evaluation support the hypothesis that trainees represent a predetermined selection of physicians who consider a career in primary care already before entering vocational training and maintain or slightly increase their motivation. At least, our findings reduce concerns raised by other studies observing that exposure to primary care contains the risk of scaring future physicians off from primary care. ${ }^{7,18}$ Since statistics showing what proportion of new PCPs participated in a vocational training program are missing, the impact of these programs on career choice cannot be measured. Consequently, evaluations of such programs should particularly focus on respondents' skills ${ }^{19}$ and knowledge gain, as well as (un-)met expectations, in order to identify target points for program tailoring.

\section{Strength and limitations}

The design of our study must be critically reviewed. The twostaged survey design enabled assessment of skills and knowledge gain without being subject to the flaws of retrospective evaluation. Still, it is an observational study based on a self- evaluation questionnaire and is, therefore, prone to cognitive biases of the respondents. Particularly anticipated career plans are to be appraised with caution. Alternative common methods of skills and knowledge evaluation that are less prone to respondents' cognitive bias include assessments by supervising physicians, direct observation and/or video reviews and clinical simulations. ${ }^{20}$ Another suitable method to check on the long-term effect on career plans would be a case-control study in medical graduates. Furthermore, limitations concerning generalizability on both the trainees' and the programme's level must be acknowledged: to enter the program, trainees need to make an application and are evaluated by staff of the Institute of Primary Care Zurich. Therefore, trainees are subject to selection phenomena not controlled in this study. Finally, it is to mention here that we present evaluation data of a specific vocational training program. Results cannot be transported to other programs, especially when featuring different education structures. This is of particular importance since our program is characterized by a rather poor standardization of the content of teaching as compared to programs in the USA, Canada, the Netherlands or Scandinavian countries, where accreditation standards are set. ${ }^{21-23}$

\section{Conclusion}

After vocational primary care training, significant increases in trainees' self-evaluated skill levels could be observed, particularly in skills that are characteristic for PCPs' role as coordinators of chronic and patient-centered care. Knowledge gain in entrepreneurship was significant, but trainees' awareness for the topic was heterogeneous. Trainees were right from the beginning highly motivated to pursue a career in primary care, but did not increasingly commit themselves to specific career plans immediately after training completion. Evaluation of training programs should, therefore, focus on operationalizing key skills of PCPs and ideally include reproducible assessments of different teaching levels, trainee skills and knowledge and include career follow-up in order to ensure quality of programs. Otherwise, statements about the effect of program implementation on national shortage of PCPs cannot be made.

\section{Acknowledgment}

The study was funded by departmental resources of the Institute of Primary Care, University and University Hospital of Zurich, Switzerland.

\section{Author contributions}

SD performed data analysis and drafted the manuscript. RT developed the questionnaire, collected data and drafted the 
manuscript. TR collected data and drafted the manuscript. SM was involved in data analysis and drafted the manuscript. All authors contributed toward data analysis, drafting and revising the paper and agree to be accountable for all aspects of the work.

\section{Disclosure}

The authors report no conflicts of interest in this work.

\section{References}

1. Buddeberg-Fischer B, Klaghofer R, Stamm M, et al. Primary care in Switzerland no longer attractive for young physicians? Swiss Med Wkly. 2006;136(31-32):520-520.

2. Tschudi P, Bally K, Zeller A. Wer will heute noch Hausarzt/ärztin werden? Umfragen bei Medizinstudierenden und Jungärzten. [Who wants to be a GP? A survey medical students and junior doctors]. Praxis (Bern 1994). 2013;102(6):335-339. German.

3. Pfarrwaller E, Sommer J, Chung C, et al. Impact of interventions to increase the proportion of medical students choosing a primary care career: a systematic review. J Gen Internal Med. 2015;30(9):1349-1358.

4. Zinn WM, Sullivan AM, Zotov N, et al. The effect of medical education on primary care orientation: results of two national surveys of students' and residents' perspectives. Acad Med. 2001;76(4):355-365.

5. Stordeur S, Leonard C. Challenges in physician supply planning: the case of Belgium. Human Res Health. 2010;8:28.

6. Tandjung R, Senn O, Marty F, Krauss L, Rosemann T, Badertscher N. Career after successful medical board examination in general practice - a cross-sectional survey. Swiss Med Wkly. 2013;143:w13839.

7. Stanley M, O'Brien B, Julian K, et al. Is training in a primary care internal medicine residency associated with a career in primary care medicine? J Gen Internal Med. 2015;30(9):1333-1338.

8. West CP, Dupras DM. General medicine vs subspecialty career plans among internal medicine residents. JAMA. 2012;308(21):2241-2247.

9. Tandjung R, Garaventa-Tadres D, Rosemann T, Djalali S. Primary care specific vocational training in Switzerland: an overview of cantonal programs. Praxis (Bern 1994). 2013;102(14):843-849.

10. Howard M, Danho S. Primary care practice transformation: start with roles and relationships. Fam Pract. 2015;32(1):1-2.

11. Buddeberg-Fischer B, Klaghofer R, Stamm M. Family physicians in Switzerland: transition from residency to family practice. Fam Med. 2011;43(1):29-36.
12. Tandjung R, Djalali S, Hasler S, Scherz N, Rosemann T, Markun S Acceptance of interventions to promote primary care: what do physicians prioritize? BMC Fam Pract. 2015;16(1):178.

13. Karsch-Volk M, Jakel K, Schneider A, Rupp A, Horlein E, Steinhauser J. [Evaluation of GP specialty training in Bavaria - an online survey among postgraduate trainees]. Z Evid Fortbild Qual Gesundhwes. 2016;113:56-65. German.

14. Buddeberg-Fischer B, Stamm M, Buddeberg C, Klaghofer R. [Young physicians' view on factors that increase the attractiveness of general practice]. Gesundheitswesen. 2008;70(3):123-128. German.

15. Lambert T, Goldacre R, Smith F, Goldacre MJ. Reasons why doctors choose or reject careers in general practice: national surveys. $\mathrm{Br} \mathrm{J} \mathrm{Gen}$ Pract. 2012;62(605):e851-e858.

16. Buddeberg-Fischer B, Stamm M, Klaghofer R. Career paths in physicians' postgraduate training - an eight-year follow-up study. Swiss Med Wkly. 2010;140:w13056.

17. Buddeberg-Fischer B, Stamm M, Marty F. Family medicine in Switzerland: training experiences in medical school and residency. Fam Med. 2007;39(9):651-655.

18. Peccoralo LA, Tackett S, Ward L, et al. Resident satisfaction with continuity clinic and career choice in general internal medicine. J Gen Internal Med. 2013;28(8):1020-1027.

19. O’Malley G, Perdue T, Petracca F. A framework for outcome-level evaluation of in-service training of health care workers. Human Res Health. 2013;11:50.

20. Epstein RM. Assessment in medical education. $N$ Engl J Med. 2007;356(4):387-396.

21. American Academy of Family Physicians. Family medicine residency curriculum guidelines. Available from:http://www.aafp.org/medicalschool-residency/program-directors/curriculum.htm. Accessed June 4, 2017.

22. The College of Family Physicians of Canada. Residency program accreditation. Available from:http://www.cfpc.ca/Residency_Program_Accreditation/. Accessed June 4, 2017.

23. Djalali S, Rosemann T. Das perfekte Curriculum für Hausarztmedizin wer hat's erfunden? Ausbildung für Hausärztinnen und Hausärzte in der Schweiz und in Europa. [Who invented the perfect curriculum? Vocational training in primary care in Switzerland and Europe]. Primary Care. 2012;12(15):290-293. German.

24. The Federal Council of the Swiss Confederation. Federal act on research involving human beings (human research act, HRA) of 30 September 2011 (status as of 1 January 2014). Available from:https://www.admin. ch/opc/en/classified-compilation/20061313/index.html. Accessed May $30,2017$.
Advances in Medical Education and Practice

\section{Publish your work in this journal}

Advances in Medical Education and Practice is an international, peerreviewed, open access journal that aims to present and publish research on Medical Education covering medical, dental, nursing and allied health care professional education. The journal covers undergraduate education, postgraduate training and continuing medical education

\section{Dovepress}

including emerging trends and innovative models linking education, research, and health care services. The manuscript management system is completely online and includes a very quick and fair peer-review system. Visit http://www.dovepress.com/testimonials.php to read real quotes from published authors. 